\title{
Increasing the Contribution of GFRP Bars on the Compressive Strength of Concrete Columns with Circular Cross Section
}

\author{
Amir Reza Tabkhi Wayghan ${ }^{a^{*}}$, Massood Mofid ${ }^{\mathrm{b}}$, Behnam Babaei Ravandi ${ }^{\mathrm{a}}$, \\ Seyed Morteza Zinati Yazdi a \\ ${ }^{a}$ Graduate Student, Department of Civil Engineering, Sharif University of Technology, Iran. \\ ${ }^{b}$ Professor, Department of Civil Engineering, Sharif University of Technology, Iran.
}

Received 09 April 2019; Accepted 11 July 2019

\begin{abstract}
Corrosion of steel in concrete elements is a major issue in concrete structures. In order to overcome this matter, Glass Fiber Reinforced Polymer (GFRP) reinforcement is being used in concrete members from almost 20 years ago. Although it has been used and developed in recent years, there are still some uncertainties for the application of FRP reinforcement, especially in concrete columns. Most codes such as ACI, CSA, JSCE \& etc. neglects the effect of these reinforcements or they do not permit them in compressive concrete elements. In this essay, it has been shown that these rebar can contribute significantly in compressive strength of concrete columns if the column confinement is provided sufficiently. In order to achieve the required confinement to reach a sharp contribution of GFRP longitudinal rebar in concrete columns, the spiral of FRP rebar with small pitches around longitudinal rebar is taken into account. This leads to higher strains of concrete which can result in a higher contribution of FRP longitudinal rebar. Foremost, equations related to the compressive strength of concrete columns considering the influence of spiral confinement will be carried out. Then, a parametric study will be performed, and the effects of pitch, concrete strength, column diameter, the quantity of longitudinal rebar and concrete cover will be investigated.
\end{abstract}

Keywords: GFRP Rebar; Confinement; Circular Concrete Column; FEM; Parametric Study.

\section{Introduction}

Reinforced concrete columns, as members of a structure which carry loads of structures, mainly compressive, are the most important members in terms of performance and the stability of concrete structures. Formerly, these columns were reinforced, only with steel reinforcements. But if these columns were placed in corrosive environments such as marine environments, the result would be the corrosion of steel reinforcements that eventually can destroy the structure. In general, corrosion of steel reinforcement is the most important factor in determining the life expectancy of concrete structures. The process of repairing structures is one of the most costly matters; therefore, in some cases, approximately, the repair and renovation of a concrete structure can cost twice the initial construction price of the structure. In Canada and the United States, billions of dollars are spent annually on the repair, renovation, and maintenance of bridges and marine structures. Governments and industrial units are looking for suitable infrastructure systems to provide more durable and more corrosion-resistant structures in order to allocate fewer funds for maintenance and repair of these structures. Regarding this, engineers around the world are looking for new and cost-effective products along with innovative approaches and systems to solve these issues. As a result, in order to meet these objectives and improve the

* Corresponding author: a.tabkhi@gmail.com

http://dx.doi.org/10.28991/cej-2019-03091377

(C) 2019 by the authors. Licensee C.E.J, Tehran, Iran. This article is an open access article distributed under the terms and conditions of the Creative Commons Attribution (CC-BY) license (http://creativecommons.org/licenses/by/4.0/). 
performance of concrete structures, a replacement was introduced as steel rebar for the reinforcement of concrete, called FRP reinforcement.

The Glass Fiber Reinforced Polymer (GFRP) rebar is the most commonly used rebar among FRP reinforcement, mainly due to its low price in comparison with other types of FRB rebar, such as CFRP and AFRP. The contribution of GFRP reinforcement in compressive strength of columns is still unclear and requires supplementary evidence to endorse its performance. At the ultimate concrete crushing strain (around 0.003), the GFRP rebar can attain only a small portion of its ultimate strength, due to its higher ultimate compressive strain (around 0.01) and its linear behaviour. In this paper, it has been tried to increase the ultimate concrete crushing strain by increasing the confinement of concrete, in order to enhance the contribution of GFRP rebar in compressive strength of columns. This could lead counting on GFRP longitudinal rebar strength on compressive behaviour of concrete columns, in spite of neglecting them, which is currently recommended by many design codes.

\section{Background}

In the past few years, a lot of research has been done on the use of FRP composites in structures. Composite FRP materials are used as internal and external reinforcing elements of concrete. The use of FRP reinforcement in concrete columns still faces uncertainties, therefore the use of this type of rebar in the report of the 440.1R Committee of ACI in 2006 [1] in columns and compression members due to lack of sufficient research is prohibited. However, by doing some research over the past years on the behaviour of concrete pressure members with FRP reinforcement, the use of these reinforcements in newer regulations, such as the report no. 40 of "fib" namely, FRP Reinforcement in RC Structures [2] and the ACI Committee's 440.1R report in 2015, these reports still have not allowed counting on the effect of FRP reinforcements on compression elements, and they neglect these rebar. The reason for this can be cited in three factors: 1: There is a few number of research in this field. 2: Low resistance and deficiency of this type of reinforcement in compression. 3: The lower contribution of this reinforcement to compression due to the low modulus of compression elasticity of these rebar, compared to steel reinforcements. In this research, we are going to increase the contribution proportion of FRP rebar in compressive concrete members with a circular section using the confinement effect of FRP rebar spirals.

Heretofore, little research has been done on the behaviour of reinforced concrete columns with FRP reinforcements. In 2012, Tobbi et al. carried out experiments on eight concrete square columns of $350 \mathrm{~mm}$ dimension, reinforced with steel rebar and GFRP, and examined the effects of the arrangement and spacing of transverse rebar. All samples had a constant ratio of longitudinal rebar (1.9\%). Two of the samples had steel rebar, and five had a GFRP rebar, and there was a sample without any reinforcement. Figure 1 shows the dimensions and properties of Tobbi's tests. By analysing and comparing results with the ACI and CSA Canadian codes, the researchers (Tobbi et al. 2012) reached the following results [3]:

- The early crushing of concrete cover reduces the axial capacity before any enclosing effect occurs. After the concrete cover was completely crushed, there was a significant increase in strength, ductility, and stiffness for the core of the concrete in highly confined specimens. These observations suggest that only the effect of the concrete core can be used in the compression calculations of the columns unless special arrangements are made to prevent the segregation of the concrete cover.

- Examining the type of cross-sectional reinforcement and their spacing showed the positive effect of GFRP reinforcement as transverse reinforcement in increasing the strength, ductility, and stiffness of the concrete core. It was also shown that if the spacing of the transverse reinforcements declines, the effect of the enclosure will increase and it will prevent the buckling of the longitudinal reinforcements. In these experiments, reducing the spacing of transverse reinforcements from $120 \mathrm{~mm}$ to $80 \mathrm{~mm}$ increased the axial capacity of the column by more than $20 \%$.

- The 0.85 reduction factor, mentioned in concrete columns for steel reinforcement accepted by different regulations can also be used for GFRP reinforcements.

- GFRP reinforcements have about $10 \%$ proportion of the whole load axial strength of the column, which is approximately equal to the proportion of steel reinforcements (about 12\%). This indicates that GFRP reinforcements have an effective contribution to pressure, provided they are properly enclosed to prevent buckling of reinforcement [3]. 


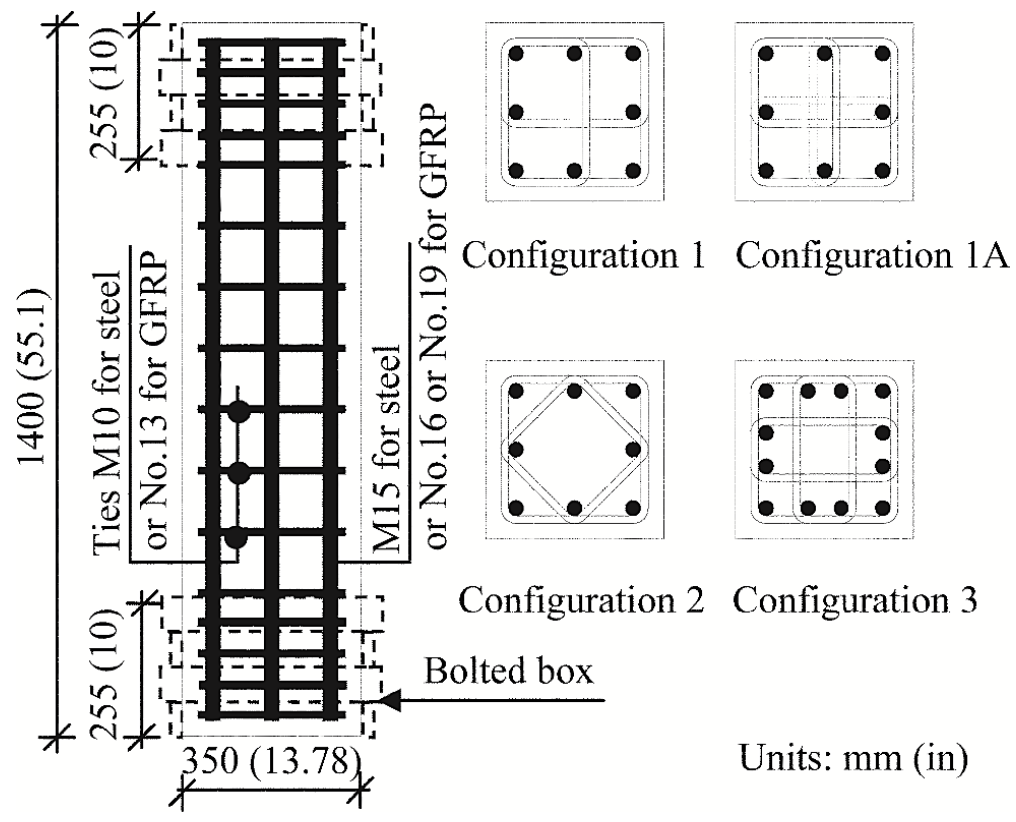

Figure 1. Various transverse rebar configurations and dimensions of Tobbi et al. experiments [3]

In 2013, Afifi studied for the experimental study of the axial behaviour of concrete columns with a circular crosssection, reinforced with GFRP and CFRP reinforcements. He tested a total of 27 circular concrete columns of 300 millimeters diameter. He categorized his samples into three groups. The first group consists of three samples, one of which is a simple concrete (without any reinforcement), and two other with steel reinforcements. The second group consists of 12 concrete columns reinforced with the GFRP longitudinal and transverse reinforcement, and the third group is identical to the second group, except that the type of reinforcement has changed from GFRP to CFRP. In these experiments, various parameters such as the type of reinforcement, the longitudinal reinforcement ratio, the volumetric spiral reinforcement ratio, the diameter of the reinforcement, the distance between the spirals, the arrangement of the transverse reinforcements, and the length of the ties' overlap were investigated. Figure 2 shows the overall view of the samples tested and some of its properties [4].

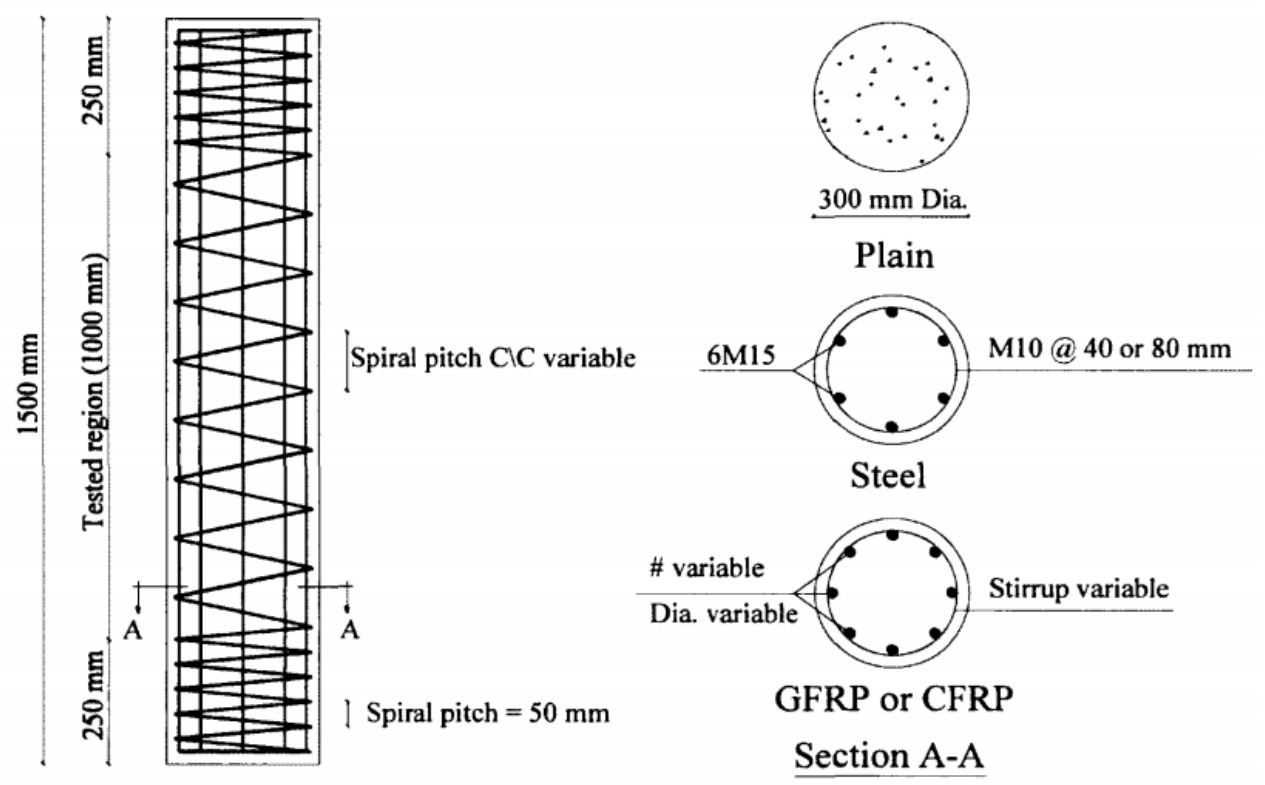

Figure 2. Overall view of Afifi's (2013) samples [4]

Some of the results of experiments conducted by Afifi (2013) can be summarized as follows:

- FRP reinforcements are effective in tolerating compressive axial stresses even after the crushing of concrete. GFRP reinforcements make up $8 \%$ of concrete capacity on average. This value is $13 \%$ for CFRP reinforcements and $15 \%$ for steel reinforcements. 
- The reinforced samples of the GFRP rebar have an average capacity of 7\% lower than the reinforced samples to the steel rebar, while the columns with CFRP rebar have an average capacity of 5\% lower in comparison with the same columns reinforced with steel rebar.

- The use of GFRP and CFRP rebar as transverse reinforcements, according to the provisions of CSA S806-12, provides sufficient buckling restraint against longitudinal reinforcements and provides proper confinement in concrete at post-peak stages.

- The study concludes that neglecting the effect of longitudinal FRP reinforcements in Canadian code (CAN/CSA S806-12) underestimates the capacity of concrete column capacity.

- The GFRP and CFRP rebar in these experiments reached up to $75 \%$ of their ultimate compressive strain, indicating the effectiveness of these rebar in bearing pressures, even after the failure of concrete [4].

Hadhood et al. (2017) and Salah-Eldin et al. (2019) performed some experimental tests on circular and square highstrength concrete columns with GFRP longitudinal and transverse rebar. They concluded that GFRP rebar can contribute on concrete strength and stiffness, similar to steel-reinforced columns in some cases $[5,6]$.

\section{Tensile Behaviour of FRP Rebar}

There is no plastic behaviour, even up to failure in FRP reinforcements, when a tensile force is applied to them, and they show a totally elastic behaviour. Consequently, there is no specific yield point for these rebar.

\section{Compressive Behaviour of FRP Rebar}

The experiments performed by $\mathrm{Wu}$ (1990) on the compressive behaviour of FRP reinforcement with a low ratio of length to diameter showed that the compressive strength of this reinforcement was less than its tensile strength. The compressive strength of FRP reinforcements for all types of GFRP, CFRP, and AFRP has been reported to be 55, 78 and $20 \%$, respectively, of their tensile strength. Also, similar results are obtained for the modulus of compression elasticity of these types of reinforcements. According to the research, experiments, and reports, the modulus of elasticity of the FRP reinforcement in compression for the GFRP, CFRP and AFRP types is reported to be 80, 85 and 100\%, respectively, of the elasticity modulus in tension $[7,8]$.

\section{Confined Concrete Behaviour}

The behaviour of the confined concrete was first investigated experimentally in 1928 by Richart et al. The purpose of this experiment was to determine the effect of stress tolerance of concrete in one direction, in the presence of stress in other directions. They concluded that the presence of confinement stresses in the lateral directions, can increase the strength of the concrete in the longitudinal direction, and in a constant quantity of lateral stresses, this increase was approximately constant and did not correlate with the concrete mixtures. In Figure 3, the effect of the lateral confinement pressure on the stress-strain diagram of concrete is shown [9].

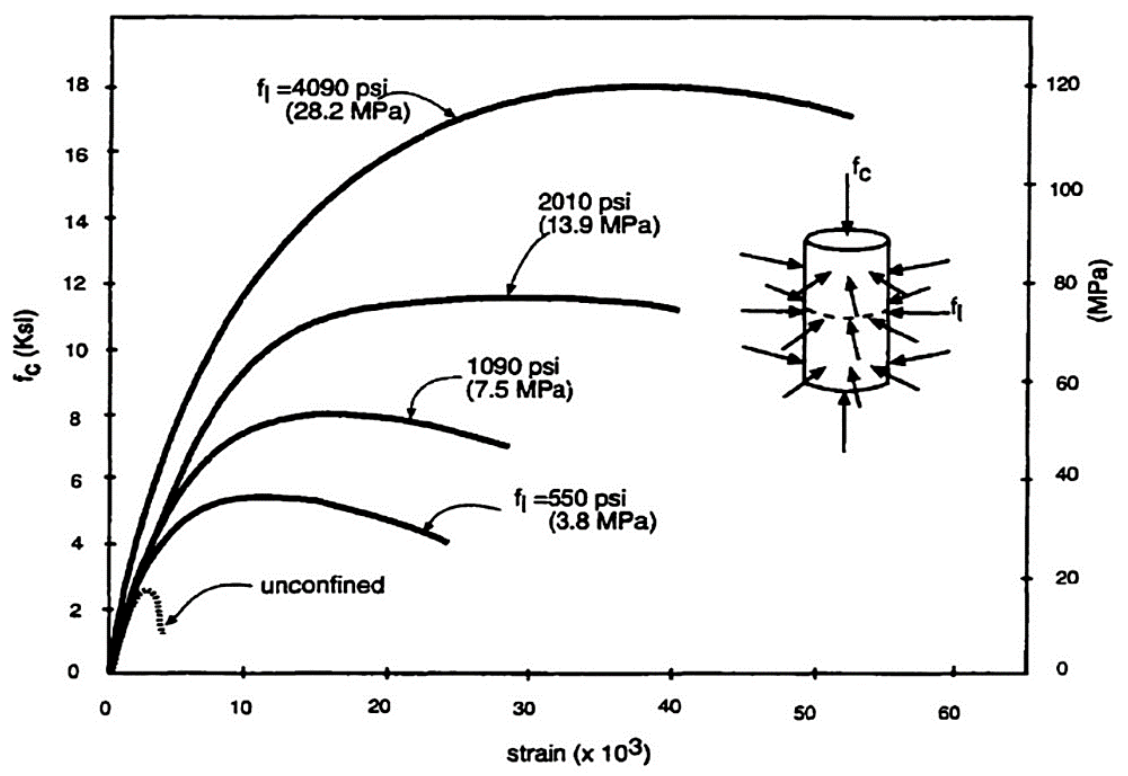

Figure 3. The effect of confinement pressure on stress-strain behaviour of concrete [9] 
Mander et al. (1988) developed a stress-strain model for concrete elements under uniaxial compressive stress and confined by transverse rebar. They proposed equations for predicting the behaviour of concrete members confined by transverse rebar such as spirals or ties. These equations are used in this research to predict the behaviour of concrete columns reinforced with GFRP rebar. Figure 4 shows the proposed stress-strain model of confined and unconfined concrete [10].

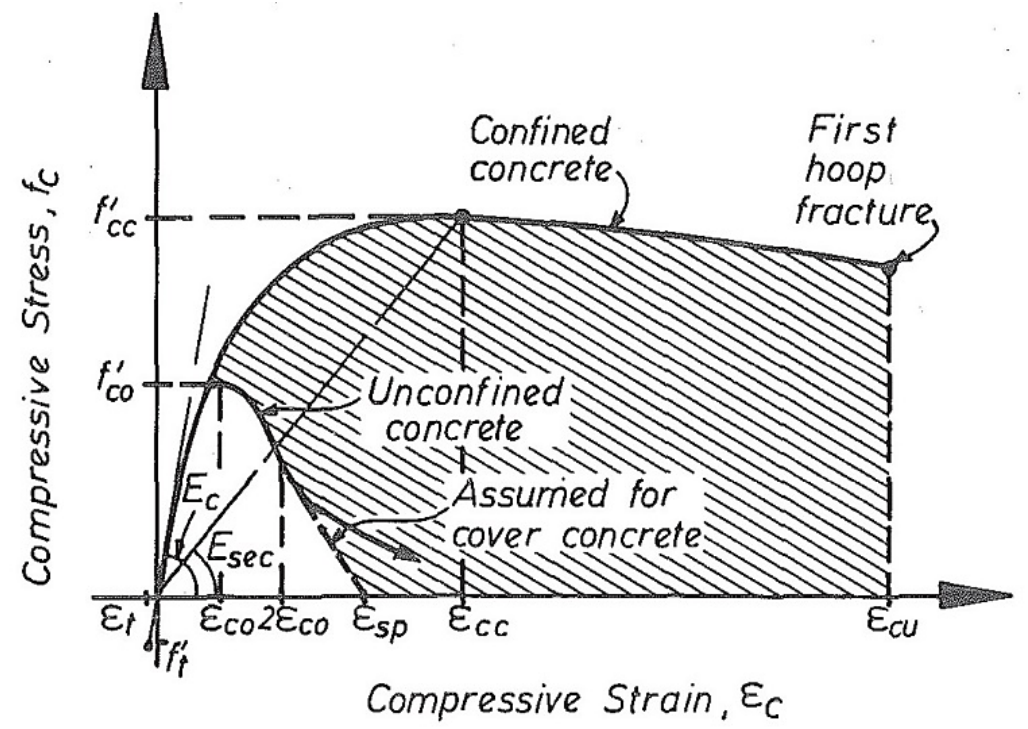

Figure 4. Proposed stress-strain model for confined and unconfined concrete by Mander et al. (1988) [10]

According to Mander et al. (1988), the confined compressive strength of the concrete column can be calculated by Equation 1 [10].

$f_{c c}^{\prime}=f_{c o}^{\prime}\left(-1.254+2.254 \sqrt{1+\frac{7.94 f_{l}^{\prime}}{f_{c o}^{\prime}}}-2 \frac{f_{l}^{\prime}}{f_{c o}^{\prime}}\right)$

Where $\mathrm{f}_{1}$ is the effective lateral confining stress from spirals given by Equation 2:

$f_{l}^{\prime}=f_{l} k_{e}$

Where $\mathrm{f}_{1}$ is the lateral pressure from the transverse reinforcement and $k_{e}$ is confinement effectiveness coefficient.

These parameters for circular cross-sections are given by Equations 3 and 4, respectively.

$f_{l}=\frac{1}{2} \rho_{s} f_{y h}=\frac{1}{2}\left(\frac{4 A_{s p}}{d_{s} s}\right) f_{y h}=\frac{2 A_{s p} f_{y h}}{d_{s} s}$

$k_{e}=\frac{A_{e}}{A_{c c}}=\frac{\frac{\pi}{4}\left(d_{s}-\frac{s^{\prime}}{2}\right)^{2}}{\frac{\pi}{4} d_{s}^{2}\left(1-\rho_{c c}\right)}=\frac{\frac{\pi}{4} d_{s}{ }^{2}\left(1-\frac{s^{\prime}}{2 d_{s}}\right)^{2}}{\frac{\pi}{4} d_{s}{ }^{2}\left(1-\rho_{c c}\right)}=\frac{\left(1-\frac{s^{\prime}}{2 d_{s}}\right)^{2}}{\left(1-\rho_{c c}\right)}$

In Equations 3 and 4, the definition of used parameters are as below and also shown in Figure 5:

$\rho_{s}$ : Ratio of the volume of transverse confining steel to the volume of confined concrete core;

$f_{y h}:$ Yield strength of the transverse rebar;

$A_{s p}:$ Area of transverse rebar;

$s$ : Center to center spacing of spiral rebar;

$A_{e}$ : The area of an effectively confined concrete core at midway between the levels of transverse reinforcement;

$A_{c c}$ : The area of concrete core.

Also, the maximum confined concrete strain can be calculated according to Equation 5 [10].

$\varepsilon_{c c}=\varepsilon_{c o}\left[1+5\left(\frac{f_{c c}^{\prime}}{f_{c o}^{\prime}}-1\right)\right]$ 


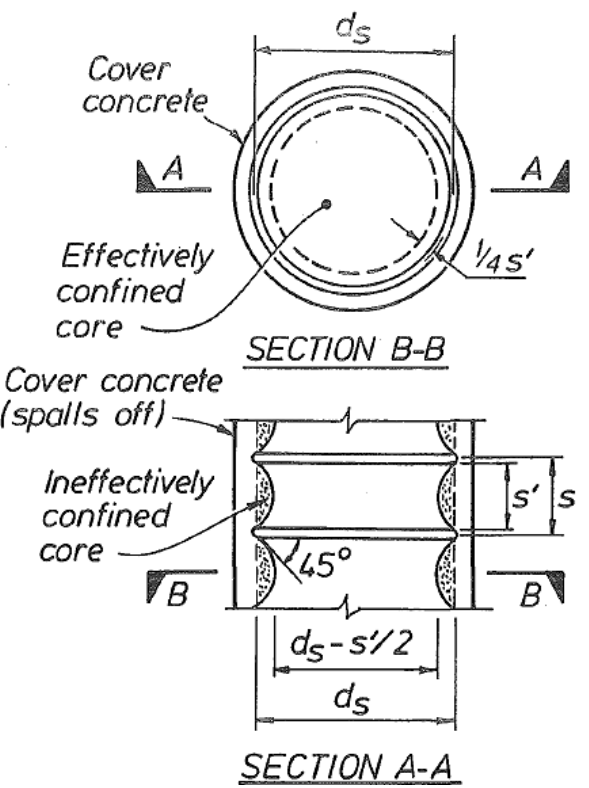

Figure 5. Effectively confined core for spiral transverse rebar by Mander et al. (1988) [10]

\section{Parametric Analysis}

In this research, the effect of spirals on the contribution of longitudinal GFRP rebar will be investigated on circular concrete columns based on Equations 1 to 5. The GFRP rebar material properties are considered as shown in Table 1.

Table 1. Material properties of considered GFRP rebar

\begin{tabular}{cccccc}
\hline Material & $\boldsymbol{\alpha}=\frac{\boldsymbol{E}_{\text {fuc }}}{\boldsymbol{E}_{\boldsymbol{f u t}}}$ & $\boldsymbol{\beta}=\frac{\boldsymbol{f}_{\boldsymbol{f u c}}}{\boldsymbol{f}_{\text {fut }}}$ & $\boldsymbol{f}_{\boldsymbol{f u t}}(\mathbf{M P a})$ & $\boldsymbol{\varepsilon}_{f u t}$ & $\boldsymbol{E}_{\text {fut }}(\mathbf{M P a})$ \\
\hline GFRP rebar & 0.8 & 0.55 & 627 & 0.014 & 44785 \\
\hline
\end{tabular}

In Table $1, E_{f u c}$ and $E_{f u t}$ are the compressive and tensile elasticity modulus of GFRP rebar, respectively. Also, $f_{f u c}$ and $f_{f u t}$ are the compressive and tensile strengths of GFRP rebar, respectively. The parameter, $\varepsilon_{f u t}$ is referred to the tensile ultimate strain of GFRP rebar. The parameters that are considered in this research are spiral pitch (center-tocenter spacing of spirals), concrete strength, column diameter, the quantity of longitudinal rebar and the clear cover of concrete.

The contribution percentage of GFRP rebar in compressive strength of circular concrete columns ("CP" parameter) is calculated based on Equation 6.

$C P=\frac{P_{1}-P_{0}}{P_{0}} \times 100$

Where $\mathrm{P}_{0}$ is the ultimate compressive strength of concrete column without any reinforcement (for the sole concrete) and is calculated according to Equation 7.

$P_{0}=0.85 \times f^{\prime}{ }_{c o} \times\left(\frac{\pi}{4} D^{2}\right)$

Also, $\mathrm{P}_{1}$ is the ultimate compressive strength of concrete column with the GFRP rebar and with the effect of confinement of spirals. $\mathrm{P}_{1}$ is calculated according to Equation 8 .

$P_{1}=0.85 \times f^{\prime}{ }_{c c} \times\left[\frac{\pi}{4}\left(d_{s}-\frac{s^{\prime}}{2}\right)^{2}\right]+\min \left\{\varepsilon_{c c} E_{f u c}, f_{f u c}\right\} \times A_{G F R P}+0.85 \times f^{\prime}{ }_{c o} \times\left[\frac{\pi}{4}\left(D^{2}-\left(d_{s}-\frac{s^{\prime}}{2}\right)^{2}\right)\right]$

The procedure of calculating the contribution percentage of GFRP rebar in compressive strength of circular concrete columns, and how confinement can increase it, is shown in Figure 6. 


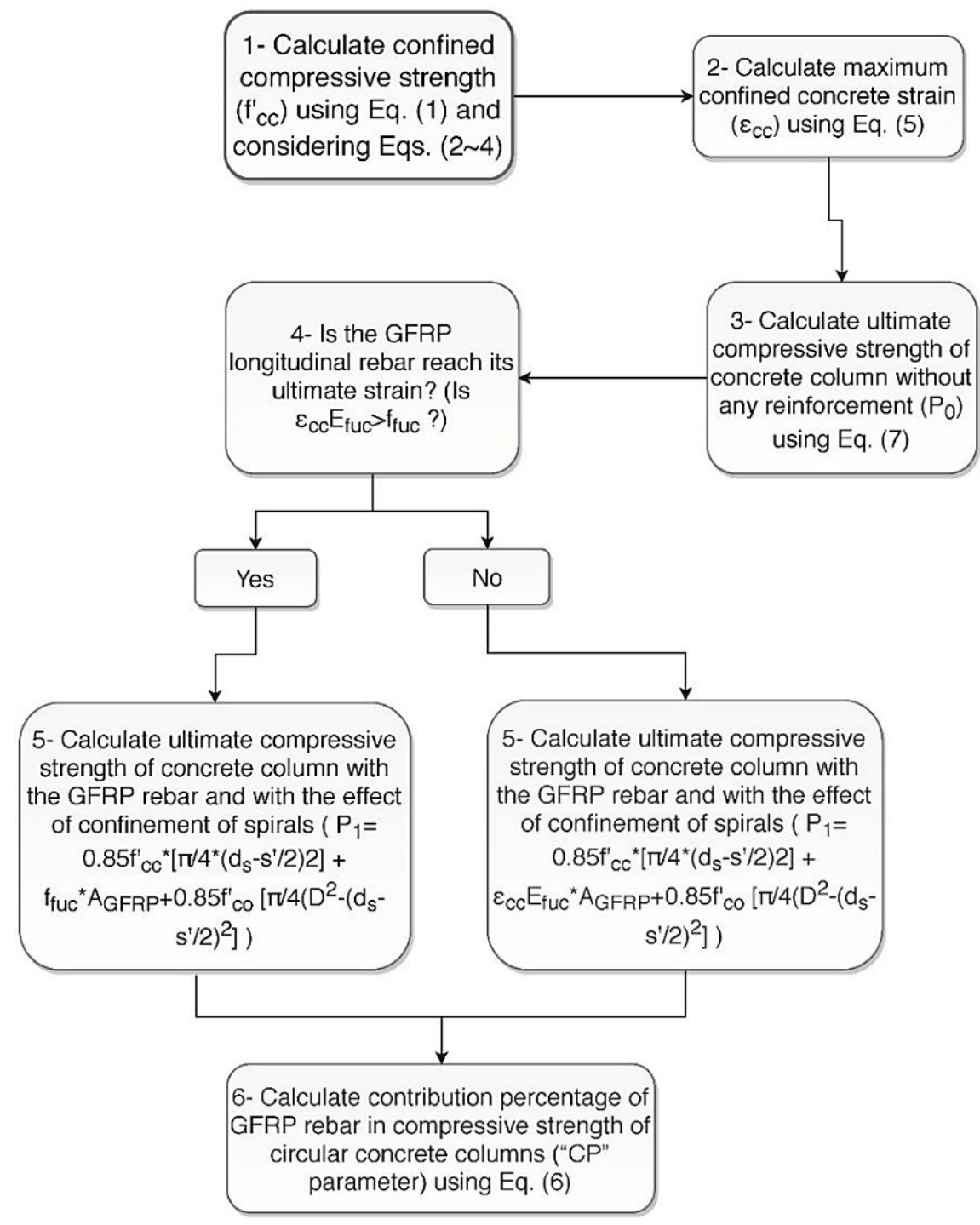

Figure 6. The flowchart for calculating the contribution percentage of GFRP rebar in compressive strength of circular concrete columns

The base sample model is considered as a $500 \mathrm{~mm}$ diameter circular column with $50 \mathrm{~mm}$ concrete cover (from the outermost edge of concrete to the center of spiral rebar). The diameter of the GFRP spiral is considered $8 \mathrm{~mm}$ with a pitch spacing of $100 \mathrm{~mm}$ and a total number of 6 longitudinal GFRP rebar with a $25 \mathrm{~mm}$ diameter is considered. The concrete strength for the base model is also assumed $35 \mathrm{MPa}$. For the parametric study, the parameters are changed with respect to this base model. For instance, for investigating the effect of spiral pitch spacing on the contribution percentage of GFRP longitudinal rebar in compressive strength of the column, this parameter (spiral pitch spacing) is altered from $50 \mathrm{~mm}$ to $250 \mathrm{~mm}$, and other parameters have remained unchanged with respect to the base model.

Figure 7 shows the influence of spiral pitch and concrete strength on contribution percentage (CP) of GFRP longitudinal rebar in the compressive strength of the concrete column. According to this figure, spiral pitch spacing has a considerable effect on the contribution of GFRP rebar. By increasing the spiral pitch spacing from $50 \mathrm{~mm}$ to $250 \mathrm{~mm}$, the GFRP rebar contribution percentage decreased from $37.8 \%$ to $5.0 \%$. Reducing the spiral pith spacing increases the confinement of the concrete column, which leads to raising the percentage of contribution of longitudinal rebar because these rebar can experience higher strains and consequently higher stresses and forces. Moreover, according to Figure 7 , it can be concluded that increasing the concrete strength $\left(\mathrm{f}_{\mathrm{c}}{ }_{\mathrm{c}}\right)$ will slightly reduce the contribution of GFRP longitudinal rebar in the axial capacity of columns. This is because as the $f^{\prime}{ }_{c}$ increases, the confinement effect will be limited. 


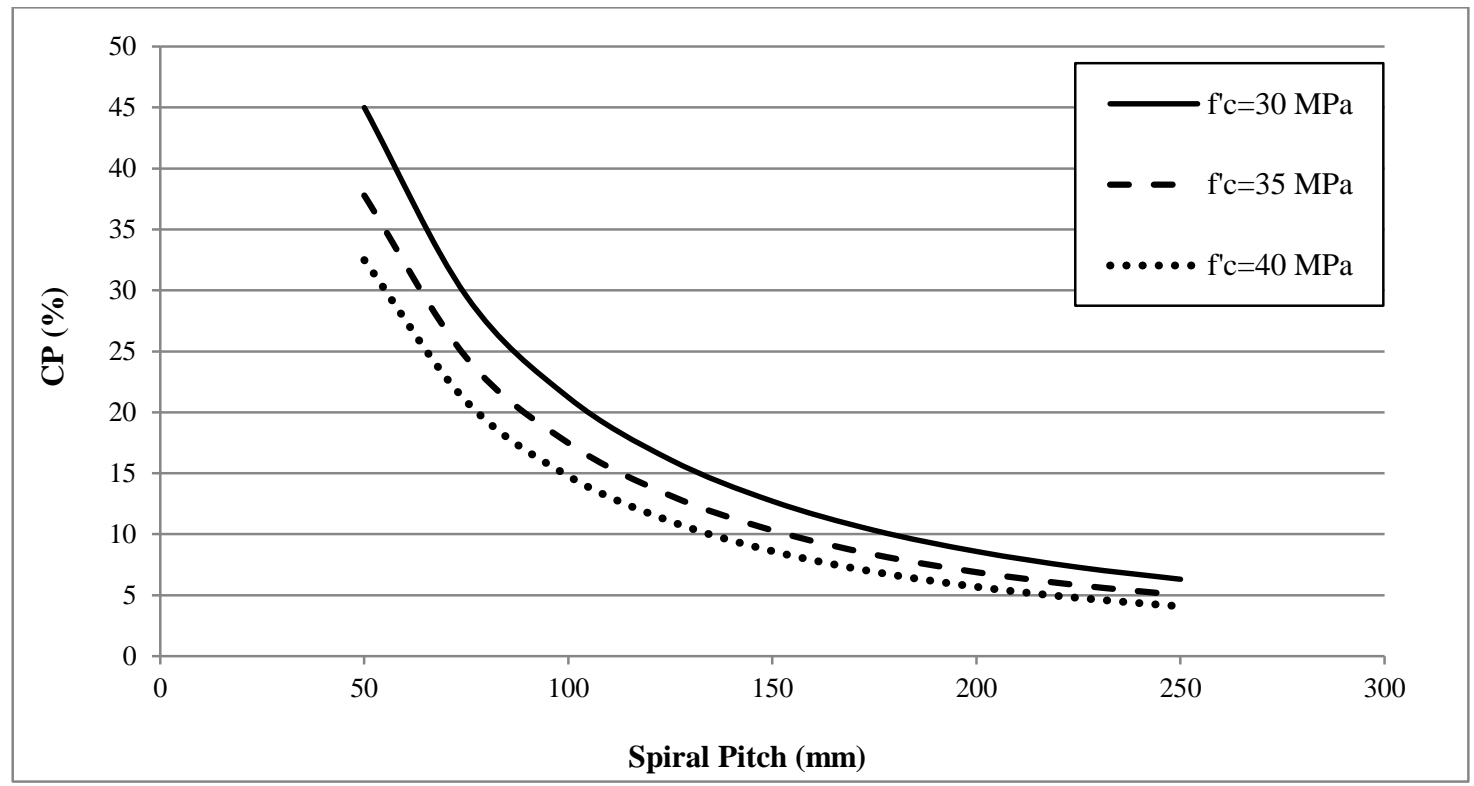

Figure 7. Spiral Pitch and Concrete Strength Effect on Contribution Percentage of GFRP Longitudinal Rebar in Compressive Strength of Column

Figure 8 shows the effect of concrete cross-section diameter on contribution percentage (CP) of GFRP longitudinal rebar in the compressive strength of the concrete column. According to this figure, the diameter of the column has a substantial influence on the contribution of GFRP rebar, such that the more dimension of column diameter, the less the contribution percentage of GFRP longitudinal rebar. By increasing column diameter from $250 \mathrm{~mm}$ to $1000 \mathrm{~mm}$, the GFRP rebar contribution percentage reduced from $43.0 \%$ to $9.8 \%$.

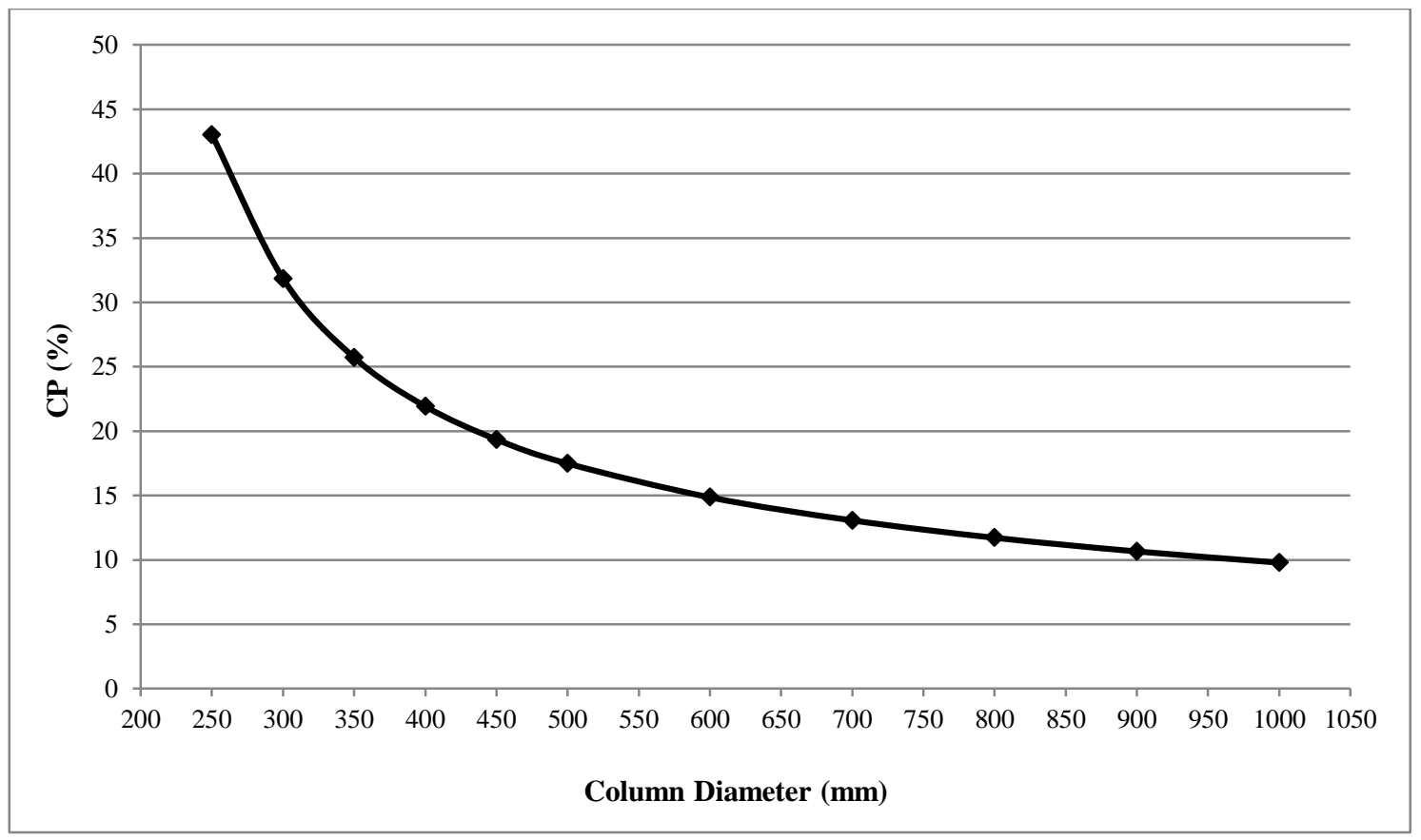

Figure 8. Column Diameter Effect on Contribution Percentage of GFRP Longitudinal Rebar in Compressive Strength of Column

Figure 9 shows the effect of quantity of longitudinal GFRP rebar on contribution percentage (CP) of GFRP longitudinal rebar in the compressive strength of the concrete column. According to this figure, as the quantity of longitudinal GFRP rebar increases, the contribution of GFRP rebar will be increased gradually and linearly. Therefore, increasing the longitudinal rebar from $1000 \mathrm{~mm}^{2}$ (which is almost equivalent to $0.5 \%$ of column gross section) to 4000 $\mathrm{mm}^{2}$ (which is almost equivalent to $2.0 \%$ of column gross section) can alter the CP factor from about $13.4 \%$ to $19.7 \%$. The reason for this is increasing in the area of longitudinal rebar in comparison with the gross cross-sectional area of the column, which yields a higher contribution. 


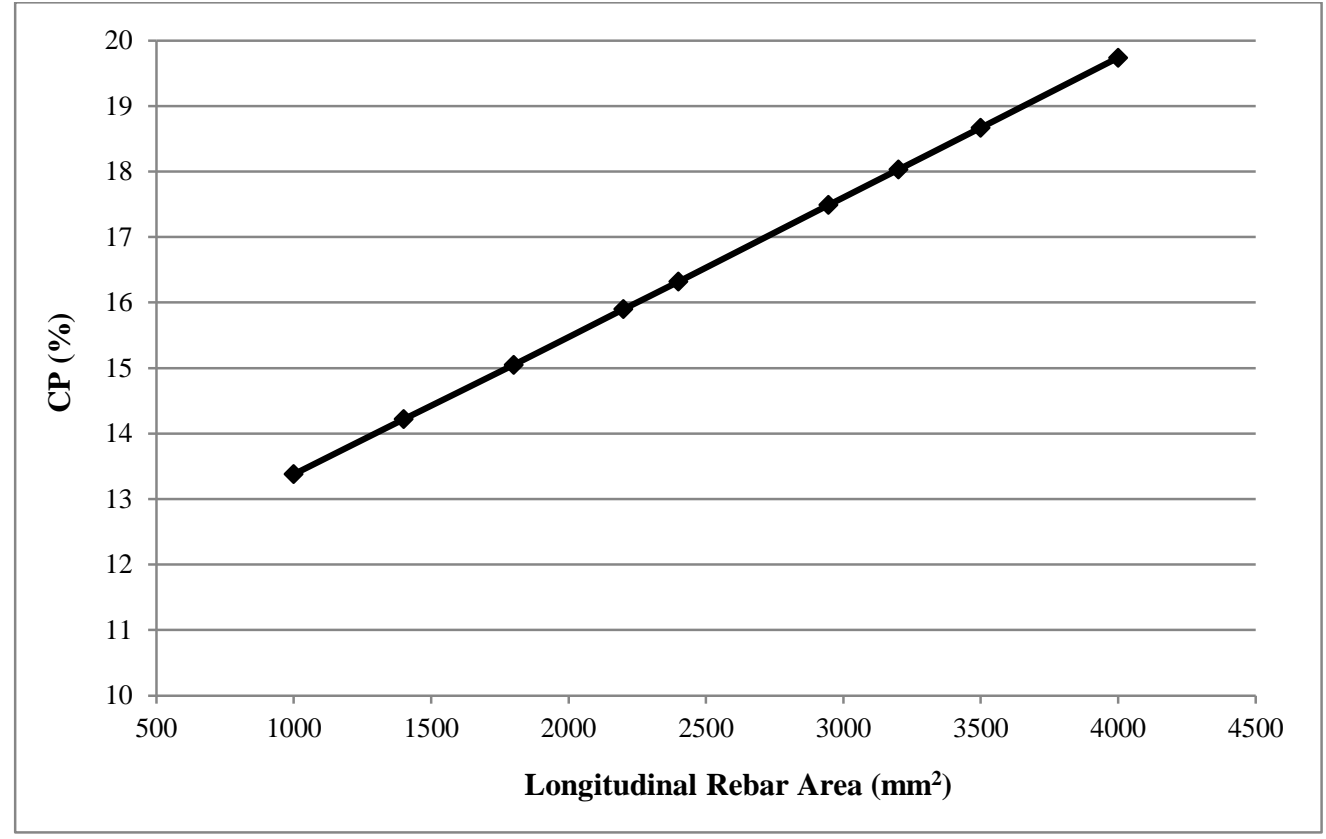

Figure 9. Quantity of Longitudinal Rebar Effect on Contribution Percentage of GFRP Longitudinal Rebar in Compressive Strength of Column

Figure 10 demonstrates the effect of concrete cover dimension on contribution percentage (CP) of GFRP longitudinal rebar in the compressive strength of the concrete column. According to this figure, the concrete cover parameter changed from $25 \mathrm{~mm}$ to $100 \mathrm{~mm}$ which is a typical range among members in various real structures. The contribution of GFRP rebar will be declined gradually and almost linearly as the concrete cover increased. However, the change in the $\mathrm{CP}$ factor is about $5.4 \%$ (from about $19.4 \%$ to $14.0 \%$ ) as concrete cover rise from $25 \mathrm{~mm}$ to $100 \mathrm{~mm}$. This is because of the reduction in the confinement area of the concrete column as the concrete cover increases, which yields a lower contribution.

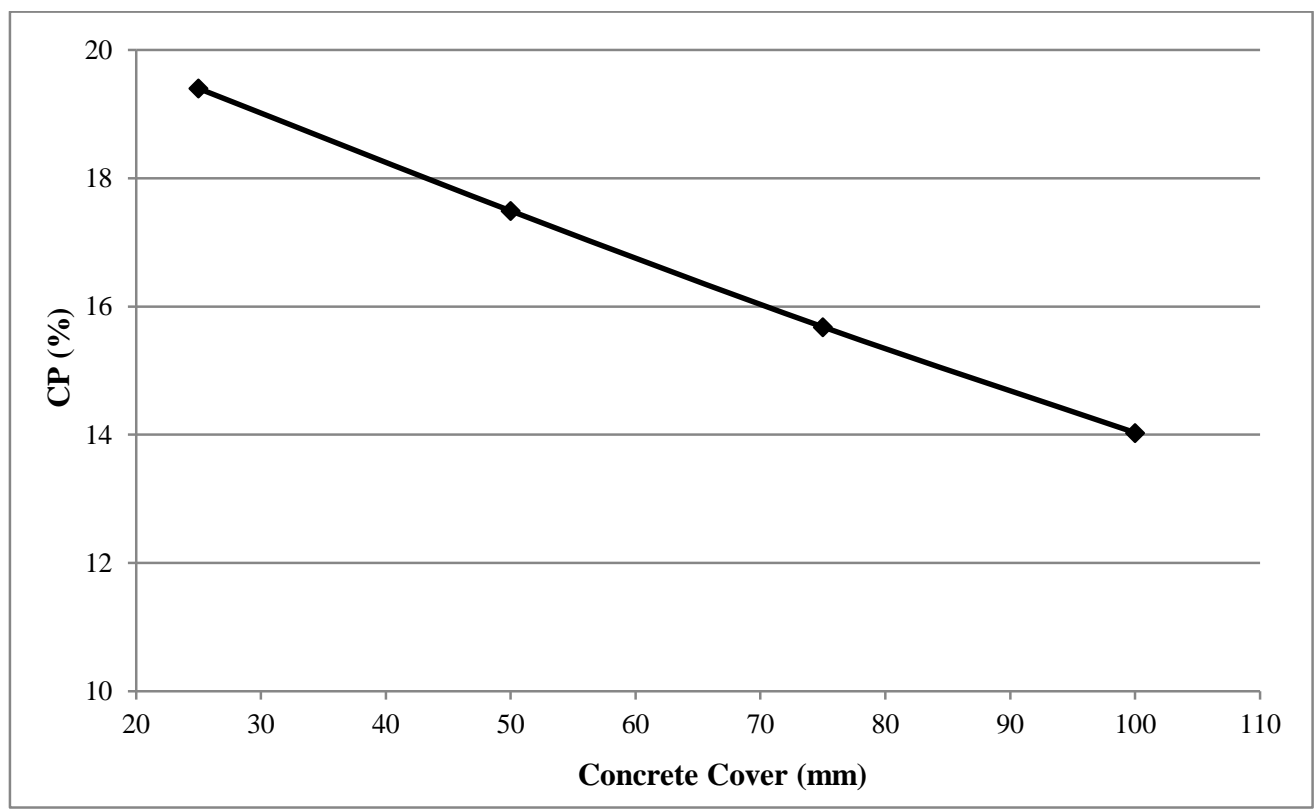

Figure 10. Concrete Cover Effect on Contribution Percentage of GFRP Longitudinal Rebar in Compressive Strength of Column

Figure 11 shows the effect of transverse rebar diameter on contribution percentage (CP) of GFRP longitudinal rebar in the compressive strength of the concrete column. According to this figure, as the size (diameter) of transverse rebar increased from $6 \mathrm{~mm}$ to $14 \mathrm{~mm}$, the contribution of GFRP rebar will be increased significantly. This is because of the confinement effect of spirals that will increase with a larger diameter (size) of spirals. 


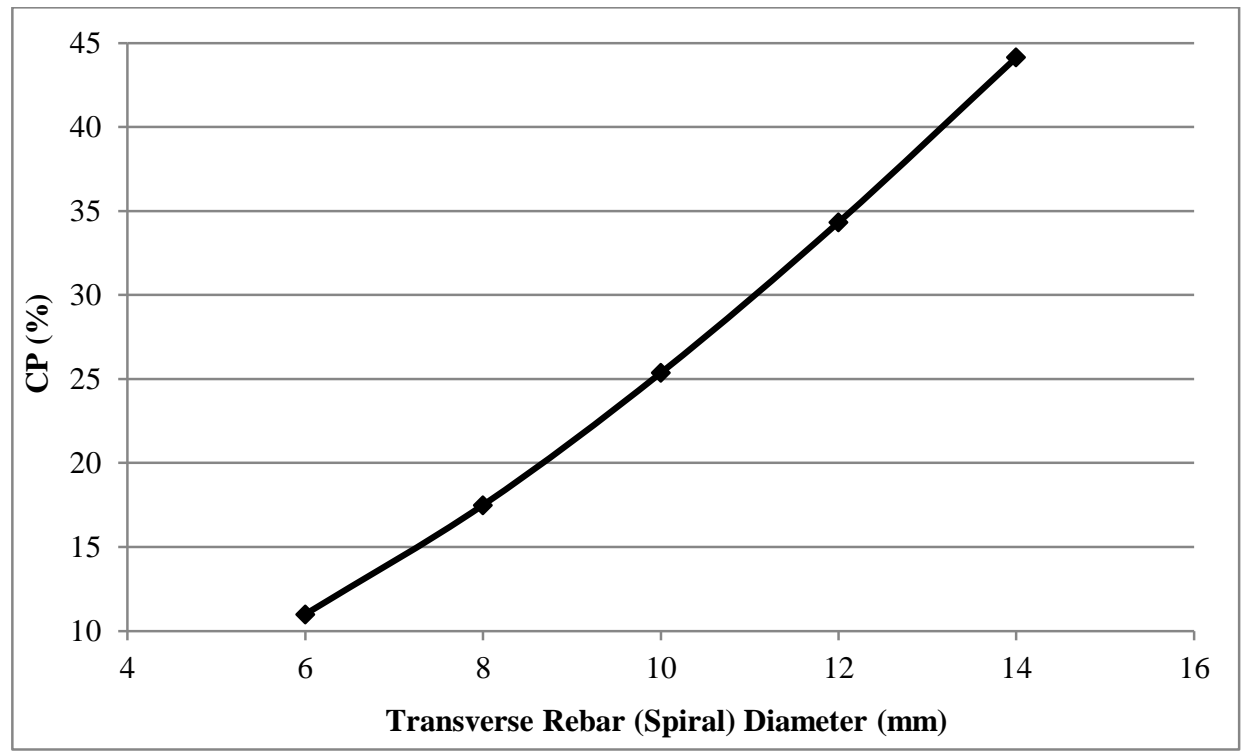

Figure 11. Size of Transverse Rebar on Contribution Percentage of GFRP Longitudinal Rebar in Compressive Strength of Column

\section{Verification}

In order to verify the results in the previous section, firstly, a numerical Finite Element Method (FEM) model using ABAQUS software was created based on Afifi's (2013) experimental test, and the results are verified. This step was performed to verify the results of the ABAQUS software. Afterward, another numerical finite element model based on the base model as defined previously was created to verify the results given in the previous section of this research.

In the ABAQUS model, the loading is applied through a rigid plate in the top of the column, monotonically, in order to avoid stress concentration on the main column and distribute the compressive force on the total area of the column. The mesh elements used in the numerical model is of 3-dimensional 8-node hexahedral elements with reduced integration (C3D8R) for concrete parts and 3-dimensional 2-node truss with reduced integration (T3D2) for GFRP rebar parts. Amiri et al. showed that these elements are proper for non-linear static and dynamic analysis and they follow the constitutive law of integration [11]. Also, the concrete material properties is defined in the software, using concrete damaged plasticity model, with dilation angle $(\psi)$ of $40^{\circ}$, shape factor for yield surface $(\mathrm{K})$ of 0.72 and ratio of initial equi-biaxial compressive yield stress to initial uniaxial compressive yield stress ( $\mathrm{fb}_{\mathrm{b}} / \mathrm{f}_{\mathrm{c}}$ ) of 1.15 [12-16].

For the first stage, the model named "G8V-3H80" by Afifi (2013) is used. This model is a 300 mm diameter circular column with 8 No. $15.9 \mathrm{~mm}$ longitudinal GFRP rebar, and spiral No. $9.5 \mathrm{~mm}$ with a pitch of $80 \mathrm{~mm}$. Figure 12 shows the 3D-model, which is created exactly the same as Afifi's (2013) experimental test model named "G8V-3H80".
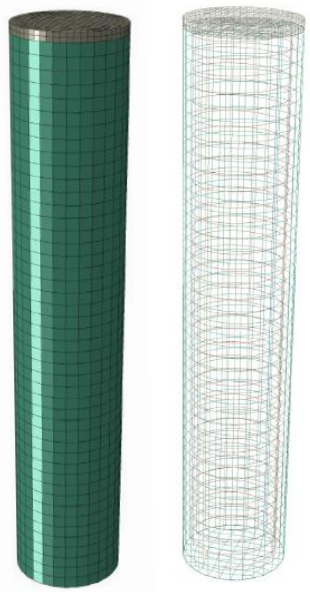

Figure 12. Overall View of Created Model in ABAQUS Software Based on Afifi's (2013) “G8V-3H80" Experimental Sample

Figure 13 compares the Load-Strain curve of the analyzed FEM model and the curve obtained from Afifi's (2013) experimental test named "G8V-3H80“. According to this figure, it can be seen that the results are very close, especially from the starting point of the curve to the ultimate load level. However, in the post-peak region, there is a modest difference which is not significant for this research. 


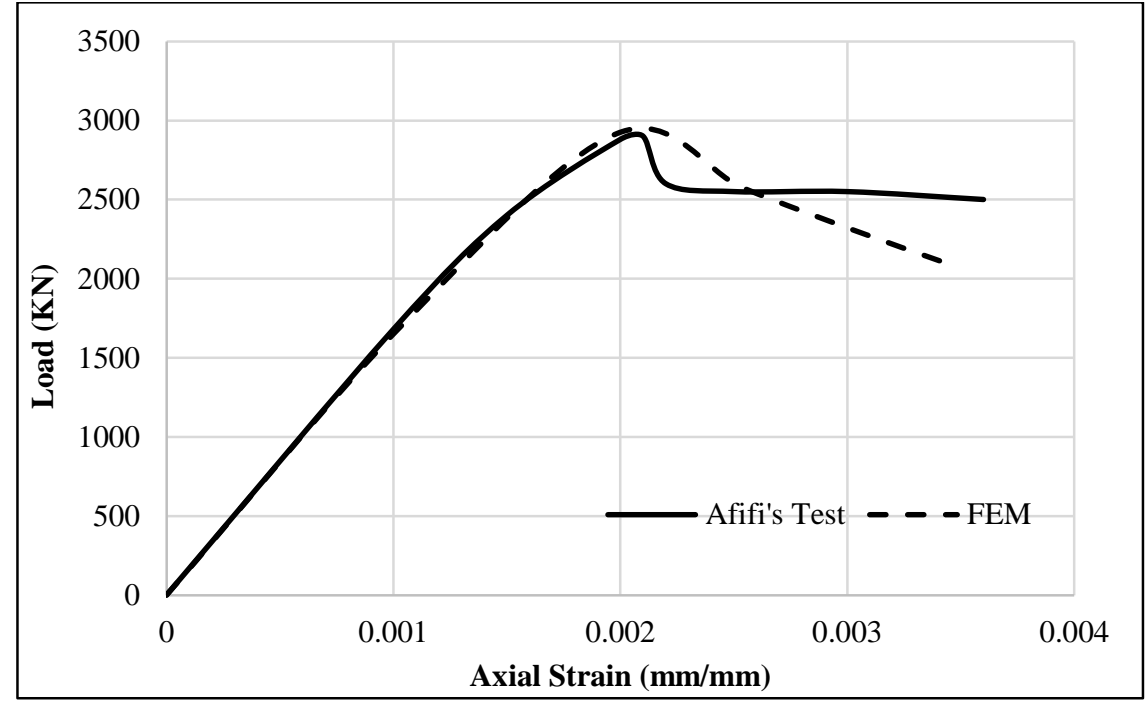

Figure 13. Comparison of the Load-Axial Strain Curves of Afifi's (2013) experimental Test versus FEM

Figure 14 demonstrates the ultimate strain of GFRP longitudinal rebar and spiral in the FEM model which is created based on Afifi's (2013) “G8V-3H80” Experimental Sample.
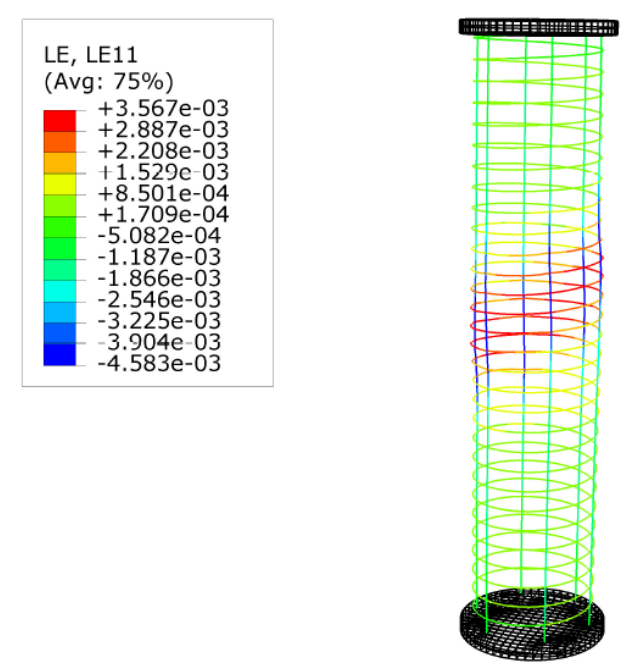

Figure 14. Ultimate Strain of GFRP Spiral and Longitudinal Rebar in the FEM Model Similar to Afifi's (2013) "G8V3H80" Experimental Sample

Figure 15 shows the maximum principal plastic strain of concrete in the FEM model which is created based on Afifi's (2013) “G8V-3H80” Experimental Sample.
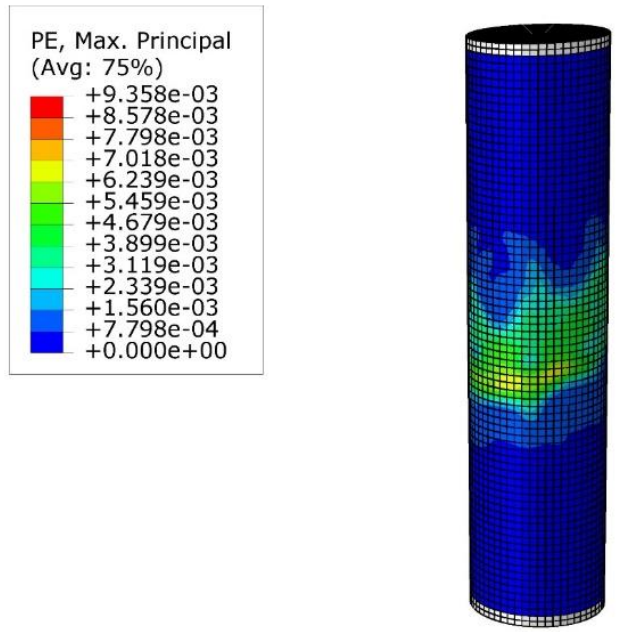

Figure 15. Maximum principal plastic strain of concrete in the FEM Model Similar to Afifi's (2013) "G8V-3H80" Experimental Sample 
In the second stage of verification, another FEM model is created to verify the results which were obtained in the earlier stage for the base model. The load-axial strain for this model is shown in Figure 16. According to this figure, the ultimate load of FEM model is about $7035 \mathrm{KN}$ which is almost $2.5 \%$ higher than the calculated axial capacity based on the method presented in the previous section, which is a negligible error.

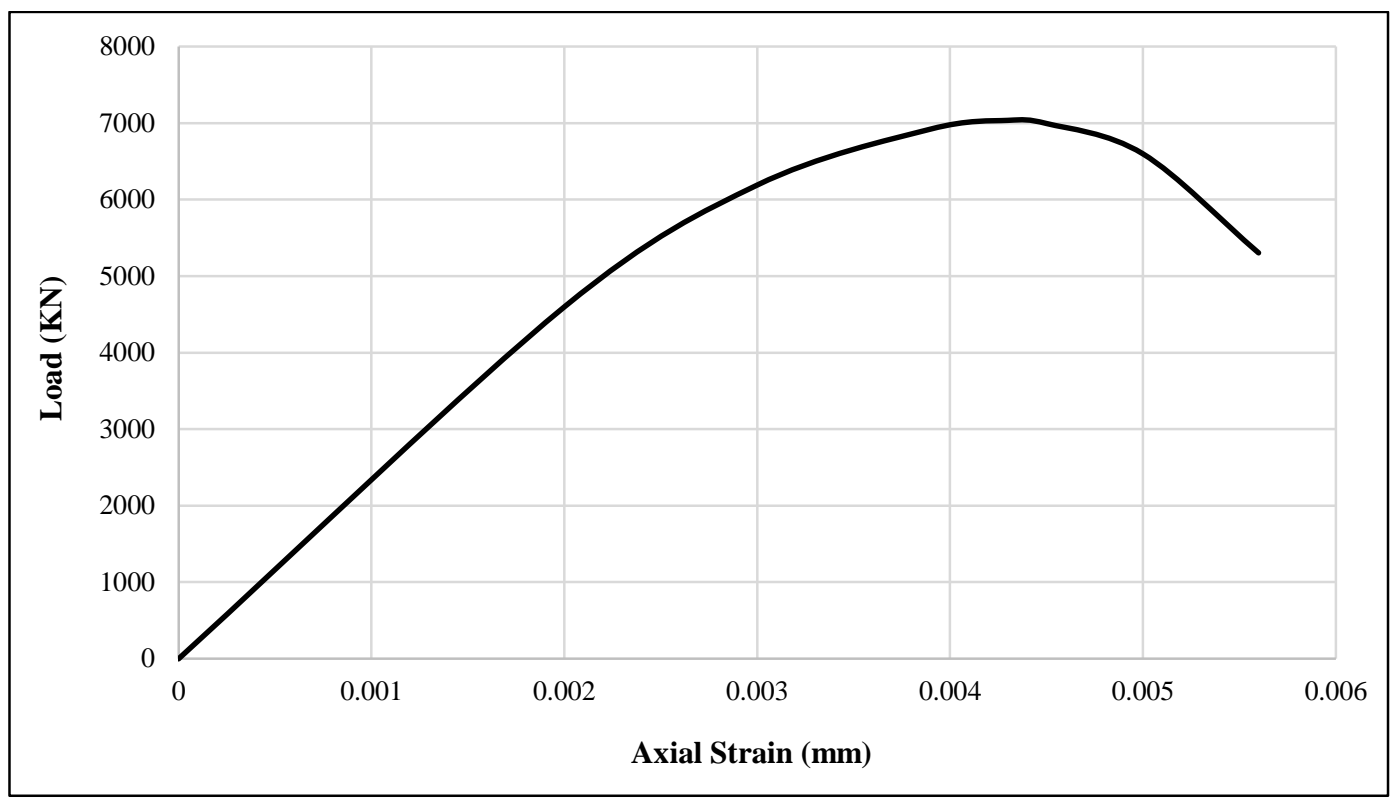

Figure 16. Load-Axial Strain Curve of FEM Model Similar to Base Model

\section{Conclusions}

In this research, the effect of parameters such as spiral pitch, size of spiral, concrete strength, concrete cover, column diameter, and longitudinal rebar area are investigated on the confinement and therefore increase of compressive axial capacity of the concrete column reinforced transversally and longitudinally with GFRP rebar. In contrary with various codes and standards such as ACI, CSA and JSCE that neglects the contribution of longitudinal GFRP rebar in compressive strength of concrete columns, it has been shown that by increasing the confinement of the concrete column (for instance by decreasing spiral pitch or concrete cover) the contribution percentage of longitudinal rebar in axial compressive strength can be enhanced, even up to $45 \%$ in the considered samples. Briefly, the following results can be concluded:

- Spiral pitch, spiral size (diameter) and column diameter are the most influential parameters affecting the contribution percentage of GFRP rebar on compressive axial strength of circular concrete columns.

- Decreasing spiral pitch from $250 \mathrm{~mm}$ to $50 \mathrm{~mm}$, increased the contribution percentage (CP) by $32.8 \%$ (from $5.0 \%$ to $37.8 \%$ ).

- Increasing spiral diameter size from $6 \mathrm{~mm}$ to $14 \mathrm{~mm}$ increased the CP parameter by $33.1 \%$ (from $11.01 \%$ to $44.1 \%$ ).

- Declining the column diameter from $1000 \mathrm{~mm}$ to $250 \mathrm{~mm}$, increased the $\mathrm{CP}$ parameter by $33.2 \%$ (from $9.8 \%$ to $43.0 \%)$.

- The parameters, concrete strength, longitudinal rebar area, and concrete cover do not change the CP parameter significantly.

- Declining the concrete cover from $100 \mathrm{~mm}$ to $25 \mathrm{~mm}$, increased the CP parameter by $5.4 \%$.

- Declining the concrete strength from $40 \mathrm{MPa}$ to $30 \mathrm{MPa}$, increased the CP parameter by $6.4 \%$.

- Increasing longitudinal rebar area from $1000 \mathrm{~mm}^{2}$ (equivalent to $0.5 \%$ of column gross section) to $4000 \mathrm{~mm}^{2}$ (equivalent to $2.0 \%$ of column gross section), increases the CP parameter by $6.3 \%$.

To conclude, the longitudinal GFRP rebar can considerably contribute to the compressive strength of concrete columns by increasing the confinement of the column. In a specific column diameter, decreasing spiral pitch and increasing spiral size are the most noticeable parameters in increasing the contribution. Subsequently, design codes' assumption of neglecting the effect of GFRP compressive rebar is conservative and it could be waived, if the confinement effects would be taken into account. 


\section{Conflicts of Interest}

The authors declare no conflict of interest.

\section{References}

[1] American Concrete Institute Committee 440. "Guide for the Design and Construction of Structural Concrete Reinforced with FRP Bars." American Concrete Institute (2006).

[2] du Béton, Fédération Internationale. "FRP reinforcement in RC structures." Task Group 9 (2007): 151.

[3] Hany Tobbi, Ahmed Sabry Farghaly, and Brahim Benmokrane. "Concrete Columns Reinforced Longitudinally and Transversally with Glass Fiber-Reinforced Polymer Bars” Structural Journal 109 (July 2012): 551-558. doi: 10.14359/51683874.

[4] Afifi, Mohammad. "Behavior of Circular Concrete Columns Reinforced with FRP Bars and Stirrups" Universite de Sherbrooke Département de génie civil, PhD diss, Québec (2013).

[5] Abdeldayem Hadhood, Hamdy M. Mohamed and Brahim Benmokrane "Experimental Study of Circular High-Strength ConcreteColumns Reinforced with GFRP Bars and Spiralsunder Concentric and Eccentric Loading" Journal of Composites for Construction 21 (April 2017): 04016078(1-12). doi: 10.1061/(ASCE)CC.1943-5614.0000734.

[6] Ashraf Salah-Eldin, Hamdy M. Mohamed and Brahim Benmokrane "Structural performance of high-strength-concrete columns reinforced with GFRP bars and ties subjected to eccentric loads" Engineering Structures 185 (April 2019): 286-300. doi: 10.1016/j.engstruct.2019.01.143.

[7] Wei-Pin Wu. "Thermomechanical Properties of Fiber Reinforced Plastic (FRP) Bars" West Virginia University, Morgantown (2013).

[8] P. K. Mallick. "Fiber Reinforced Composites, Materials, Manufacturing, and Design, Third Edition" (November 19, 2007). doi: $10.1201 / 9781420005981$.

[9] Frank Erwin Richart, Anton Brandtzæg and Rex Lenoi Brown. "A Study of the Failure of Concrete under Combined Compressive Stresses" University of Illinois at Urbana Champaign (1928).

[10] John B. Mander, Michael John Nigel Priestley and R. Park and Brahim Benmokrane. “Theoretical Stress - Strain Model for Confined Concrete” Journal of Structural Engineering 114 (September 1988): 1804-1826. doi: 10.1061/(asce)0733-9445

[11] Amir Mohammad Amiri, Amin Olfati, Shima Najjar, Peyman Beiranvand and M.H. Naseri Fard. "The Effect of Fly Ash on Flexural Capacity Concrete Beams" Advances in Science and Technology Research Journal 10(30) (June 2016): 89-95. doi:10.12913/22998624/62630.

[12] Mohamed Elchalakani, Ali Karrech, Minhao Dong, M.S.Mohamed Ali and Bo Yang "Experiments and Finite Element Analysis of GFRP Reinforced Geopolymer Concrete Rectangular Columns Subjected to Concentric and Eccentric Axial Loading" Structures 14 (June 2018): 273-289, doi: 10.1016/j.istruc.2018.04.001

[13] Mohamed Elchalakani, Ali Karrech, M.F. Hassanein and Bo Yang, "Plastic and yield slenderness limits for circular concrete filled tubes subjected to static pure bending" Thin-Walled Structures 109 (December 2016): 50-64, doi: 10.1016/j.tws.2016.09.012.

[14] Ali Karrech, Thomas Poulet \& Klaus Regenauer-Lieb “A limit analysis approach to derive a thermodynamic damage potential for non-linear geomaterials” Philosophical Magazine 92 (October 2012): 3439-3450. doi: 10.1080/14786435.2012.687469.

[15] Athanasios I. Karabinis, Theodoros C. Rousakis “Concrete confined by FRP material: a plasticity approach” Engineering Structures 24 (July 2002): 923-932, doi: 10.1016/S0141-0296(02)00011-1.

[16] Ali Karrech, Fethi Abbassi, Hakan Basarir and Mostafa Attar "Self-consistent Fractal Damage of Natural Geo-materials in Finite Strain” Mechanics of Materials 104 (January 2017): 107-120. doi: 10.1016/j.mechmat.2016.08.017. 